\title{
Family Medicine and Community Health \\ Experiences of new family physicians finding jobs with obstetrical care in the USA
}

\author{
Aimee R Eden, ${ }^{1}$ Tyler Barreto, ${ }^{2}$ Elizabeth Rose Hansen ${ }^{1}$
}

To cite: Eden AR, Barreto T, Hansen ER. Experiences of new family physicians finding jobs with obstetrical care in the USA. Fam Med Com Health 2019;7:e000063. doi:10.1136/ fmch-2018-000063

Received 16 November 2018 Revised 20 February 2019 Accepted 22 February 2019

\section{Check for updates}

(C) Author(s) (or their employer(s)) 2019. Re-use permitted under CC BY-NC. No commercial re-use. See rights and permissions. Published by BMJ.

${ }^{1}$ Department of Research and Policy, American Board of Family Medicine, Lexington, Kentucky, USA

${ }^{2}$ Family and Community Medicine, University of Texas Health Science Center at San Antonio, San Antonio, Texas, USA

Correspondence to

Dr Aimee R Eden;

aeden@theabfm.org

\section{ABSTRACT}

Objective This study aimed to explore how new family medicine graduates who want to include obstetrics in their scope of practice identify and select jobs and to understand how employment influences scope of practice in family medicine, particularly the ability to provide maternity care and deliver babies.

Design Mixed-methods study including a survey and qualitative interviews conducted in 2017.

Setting We electronically surveyed US family physicians and followed up with a purposeful subsample of these physicians to conduct in-depth, semistructured telephone interviews.

Participants 1016 US family medicine residency graduates 2014-2016 who indicated that they intended to deliver babies in practice completed a survey; 56 of these were interviewed.

Main outcome measures The survey measured the reasons for not doing obstetrics as a family physician. To identify themes regarding finding family medicine jobs with obstetrics, we used a team-based, immersioncrystallisation approach to analyse the transcribed qualitative interviews.

Results Survey results (49\% response rate) showed that not finding a job that included obstetrics was the primary reason newly graduated family physicians who intended to do obstetrics were not doing so. Qualitative interviews revealed that family physicians often find jobs with obstetrics through connections or recruitment efforts and make job decisions based on personal considerations such as included geographical preferences, family obligations and lifestyle. However, job-seeking and job-taking decisions are constrained by employment-related issues such as job structure, practice characteristics and lack of availability of family medicine jobs with obstetrics.

Conclusions While personal reasons drove job selection for most physicians, their choices were constrained by multiple factors beyond their control, particularly availability of family medicine jobs allowing obstetrics. The shift from physician as practice owner to physician as employee in the USA has implications for job-seeking behaviours of newly graduating medical residents as well as for access to healthcare services by patients; understanding how employment influences scope of practice in family medicine can provide insight into how to support family physicians to maintain the scope of practice they desire and are trained to provide, thus, ensuring that families have access to care.

\section{INTRODUCTION}

With a growing obstetric provider shortage and maldistribution in the USA, ${ }^{1}$ family physicians who provide obstetric care are crucial to ensuring access. ${ }^{2-4}$ However, the declining number of family physicians including obstetric care in their practice has been well documented, and today, fewer than $10 \%$ of currently practising family physicians are delivering babies. ${ }^{5-7}$ Researchers have identified significant gaps between training and practice of maternity care and between intention and practice of obstetrics. A recent study showed that while over $90 \%$ of 2013 family medicine graduates reported that they were adequately prepared in maternity care, just $25 \%$ of these physicians doing outpatient continuity care were providing any maternity care in $2016 .^{8}$ Of 2014-2016 family medicine graduates, $23 \%$ intended to include obstetric deliveries in practice, yet fewer than $10 \%$ were doing so. 5

Many explanations for this decline have been considered, including cost of malpractice, lifestyle constraints, difficulty getting and maintaining privileges and inadequate training. ${ }^{9-15}$ These reasons do not tell a complete story. Contrary to previous research, ${ }^{10} 15$ of 2013 family medicine residency graduates who were interested in delivering babies but who were not doing so in practice 3 years later $(n=856)$, few reported malpractice costs $(24 \%)$ or privileging challenges $(15 \%)$ as barriers to doing deliveries. However, $60 \%$ indicated that there was no opportunity to do deliveries in the practice they joined, ${ }^{16}$ raising questions about constraints placed on family physicians by employers or hospitals.

Shifts in physician employment, from practice ownership to becoming employees of hospitals or medical groups, have been documented over the past decades. The 2016 Survey of America's Physicians found that just $33 \%$ of physicians identified as 
independent practice owners or partners, a significant decline from just 4 years earlier in 2012, when almost $49 \%$ were practice owners. Conversely, the 2016 data showed that $58 \%$ were employed either by a hospital or a medical group, up from $44 \%$ in $2012 .{ }^{17}$ An analysis of the American Medical Association 2016 Physician Practice Benchmark Survey found that $50 \%$ of family physicians were employees rather than owners of the practices in which they worked. ${ }^{18}$ The decline in practice ownership is underlined by evidence that in 2016, younger physicians are less likely to have an ownership stake in their practice $(28 \%$ among physicians under the age of 40) than older physicians (55\% among physicians age 55 and older), and correspondingly, younger physicians were more than three times as likely as older physicians to be employed by hospitals ( $14 \%$ vs $4 \%){ }^{18}$ Employed physicians likely face different challenges than those practising in physician-owned offices, and it is unknown the extent to which employers might influence the scope of practice of family physicians. For new family medicine graduates seeking employment, it is unknown how the ability to practice full scope family medicine, including obstetrics, may be impacted by the organisational structure and culture of potential employers.

Previous studies have explored the characteristics of physicians who practice in rural areas ${ }^{1920}$ and family physicians and residency programme characteristics for those who intend to provide maternity care. ${ }^{21}$ None have investigated how broader health system shifts or other external factors may impact family physician ability to practice maternity care. Similarly, previous research has investigated how physicians choose their specialty post-medical school, ${ }^{22-26}$ but to our knowledge, none have focused on how physicians identify and choose jobs post-residency, the factors that constrain and facilitate their decisions or their experiences in the process. This qualitative study aimed, in part, to better understand the complexities and experiences of finding a job that includes obstetrics as a family physician.

\section{METHODS}

This mixed-methods exploratory study, conducted in 2017, included a brief electronic survey and individual, semistructured interviews. A five-question survey was sent to all 2098 family physicians who graduated from residency between 2014 and 2016 who reported intention to include obstetric deliveries in practice on the American Board of Family Medicine (ABFM) Certification Examination Registration Practice Demographic Questionnaire (full survey analysis and findings have been reported elsewhere ${ }^{27}$ ). Family physicians in the same cohort who did not indicate intention to include obstetrics in practice were excluded from the study $(\mathrm{n}=7451)$. The data analysis for this paper was generated using SAS software (V.9.4).
The qualitative portion of the study included semistructured interviews with a sample of physicians who had responded to the survey and agreed to participate in a follow-up interview and provided contact information. Of those who agreed to be interviewed, we selected physicians who were and were not including deliveries in their current practice, aiming for a sample of half who were delivering babies and half who were not. To ensure we interviewed a diverse group, we purposefully identified physicians based on responses to survey questions: for those who were delivering, we recruited physicians who reported different volumes of obstetrical deliveries and for those who were not delivering, we recruited physicians who gave different reasons for not doing so. In all cases, we tried to ensure geographic variation in our sample: physicians practising in different regions, and accounting for rurality/urbanicity using Rural Urban Commuting Area codes associated with current practice address from ABFM demographic data. ${ }^{28}$ We sent email invitations to a subsample to participate in an interview.

We used a semistructured interview guide that included questions about residency maternity care training, job-seeking strategy and decision-making, experience obtaining hospital privileges and malpractice insurance and current practice scope and structure. This paper focuses on questions about how physicians found their current position and how they made the decision to apply for and take their current position. Experienced researchers (AE, TB, EH) conducted 45-60 min interviews by telephone. Interviews were recorded and professionally transcribed. Informed consent was obtained from each participant prior to conducting the interviews.

The 'immersion-crystallisation' approach, which involved cycles of concentrated textual review of data, was applied to first code data using a priori codes aligned with the interview guide and based on previous research, and to generate emergent codes as they arose in through the iterative process. ${ }^{29}$ We then subcoded where the original coding was too broad to make sense of physician experience or where further nuanced themes or patterns were identified. Where possible, we grouped codes into meaningful categories to further organise the data and identify patterns and themes. We employed qualitative data analysis software, MAXQDA software (V.2018, VERBI Software, Berlin, Germany), to manage the coding process. The authors met on a weekly basis to ensure inter-rater agreement. In the early phases of data analysis, all three team members (AE, TB, EH) coded the same interviews independently, meeting regularly to compare coded segments to ensure uniformity and to discuss and refine the codes and code definitions. We were consistently applying the codes after seven independently coded interviews, after which we divided the remaining interviews among us to code, continuing to meet weekly to discuss questionable or newly emerging themes. All interviews were fully coded using our final codebook, though after 18 interviews 
Table 1 Personal and practice characteristics of interviewees by provision of obstetrical deliveries

\begin{tabular}{|c|c|c|c|c|}
\hline & \multicolumn{2}{|c|}{$\begin{array}{l}\text { Provides } \\
\text { obstetrics } \\
(n=29)\end{array}$} & \multicolumn{2}{|c|}{$\begin{array}{l}\text { Do not provide } \\
\text { obstetrics } \\
(n=27)\end{array}$} \\
\hline & $\mathbf{n}$ & $\%$ & $\mathbf{n}$ & $\%$ \\
\hline Female & 19 & 65.5 & 13 & 48.1 \\
\hline Male & 10 & 34.5 & 14 & 51.9 \\
\hline MD & 23 & 79.3 & 20 & 74.1 \\
\hline DO & 6 & 20.7 & 7 & 25.9 \\
\hline IMG & 4 & 13.8 & 4 & 14.8 \\
\hline Average age & 33.2 & & 34.4 & \\
\hline Age range & $28-53$ & & $29-54$ & \\
\hline \multicolumn{5}{|l|}{ Practice location } \\
\hline Urban & 17 & 58.6 & 20 & 74.1 \\
\hline Large rural & 3 & 10.3 & 4 & 14.8 \\
\hline Small rural & 7 & 24.1 & 2 & 7.4 \\
\hline Isolated & 2 & 6.9 & 1 & 3.7 \\
\hline \multicolumn{5}{|l|}{ Repayment obligations } \\
\hline Military & 1 & 3.4 & 4 & 14.8 \\
\hline $\begin{array}{l}\text { National Health Service } \\
\text { Corps }\end{array}$ & 3 & 11.1 & 3 & 10.3 \\
\hline
\end{tabular}

DO, Doctor of Osteopathic Medicine; IMG, International Medical Graduate; MD, Doctor of Medicine.

had been coded, no new themes were identified, indicating that we had reached thematic saturation.

\section{RESULTS}

Of 1016 survey respondents (an almost $50 \%$ response rate), $31 \%$ reported they are not currently including obstetric deliveries in their practice; of these $41 \%$ reported that finding a job without $\mathrm{OB}$ was in the top three reasons for not currently practising obstetrics; $26 \%$ reported it as the number one reason. Of the physicians who completed the five-question survey, $56 \%(\mathrm{n}=565)$ indicated willingness to be interviewed. While those currently including obstetric deliveries were significantly more likely to agree to be interviewed than those not including obstetrics $(63.7 \%$ and $40.5 \%$, respectively, $\mathrm{p}<0.001$ ); we interviewed $(\mathrm{N}=56$ ) a balanced sample from each group, 29 currently delivering babies and 27 not currently delivering babies. Table 1 includes demographic information about the interviewees (more detailed survey findings are reported elsewhere ${ }^{27}$ ).

The themes that emerged from the interviews regarding identifying and selecting a job post-residency fell into three primary categories: the mechanism through which family physicians identified a job (how they found a job); the factors that went into decisions around identifying and taking a job (why they took a job); and challenges faced by family physicians when trying to find a job including obstetrics.

\section{Job identification mechanism}

Interviewees discussed various mechanisms through which they identified jobs (figure 1), including connections (personal contacts or professional connections such as an advisor or mentor), recruiters or recruitment agencies, word-of-mouth or online (including National Health Service Corps listings, state level listings or other online job search formats). Five family physicians were military, so their placements were assigned for them, with generally minimal physician control over job scope; four of them were not currently doing deliveries. Connections, whether personal or professional, were the most common mechanism for identifying a job for family physicians doing and not doing deliveries. However, more physicians doing deliveries discussed connections helping them to identify a job than those not doing deliveries. The use of recruiters or recruiting agencies was the second most commonly discussed mechanism for finding a job; however, only 11 physicians mentioned this method.

\section{Job decision-making factors}

The reasons physicians gave for taking a job were nuanced and often interrelated. These factors were grouped into four themes, described below and defined in table 2 with corresponding illustrative quotes.

\section{Personal influences and preferences}

By far, personal influences were the most frequently expressed considerations for taking a job, including geography or location, family and lifestyle or balance. Both family physicians doing deliveries and those who were not mentioned location as a key constraint or consideration, whether looking for a job in a particular city, region or geography. Similarly, family or spousal influences were discussed equally by physicians doing and not doing deliveries. Often, family considerations drove the geographical choice.

\section{Job characteristics}

Issues directly related to the job structure or other job characteristics, which interviewees did not perceive to be open for negotiation or under their control, came up in many interviews. For physicians doing obstetrics, practice features (size, structure, composition) were an important factor in deciding to accept a job, as was a call schedule conducive to their lifestyle. When call was discussed by those not doing obstetrics, it was in the context of non-ideal call schedules or lack of a call sharing method. A few physicians mentioned financial considerations such as getting paid enough or too little to include obstetrics in their practice.

\section{Professional considerations and career goals}

Individual professional considerations also contributed to job search and choice for many physicians. While related to job characteristics described above, unlike fixed job factors, these elements were characterised by a sense of control over their own career path. Some physicians not doing obstetrics discussed making a compromise of 


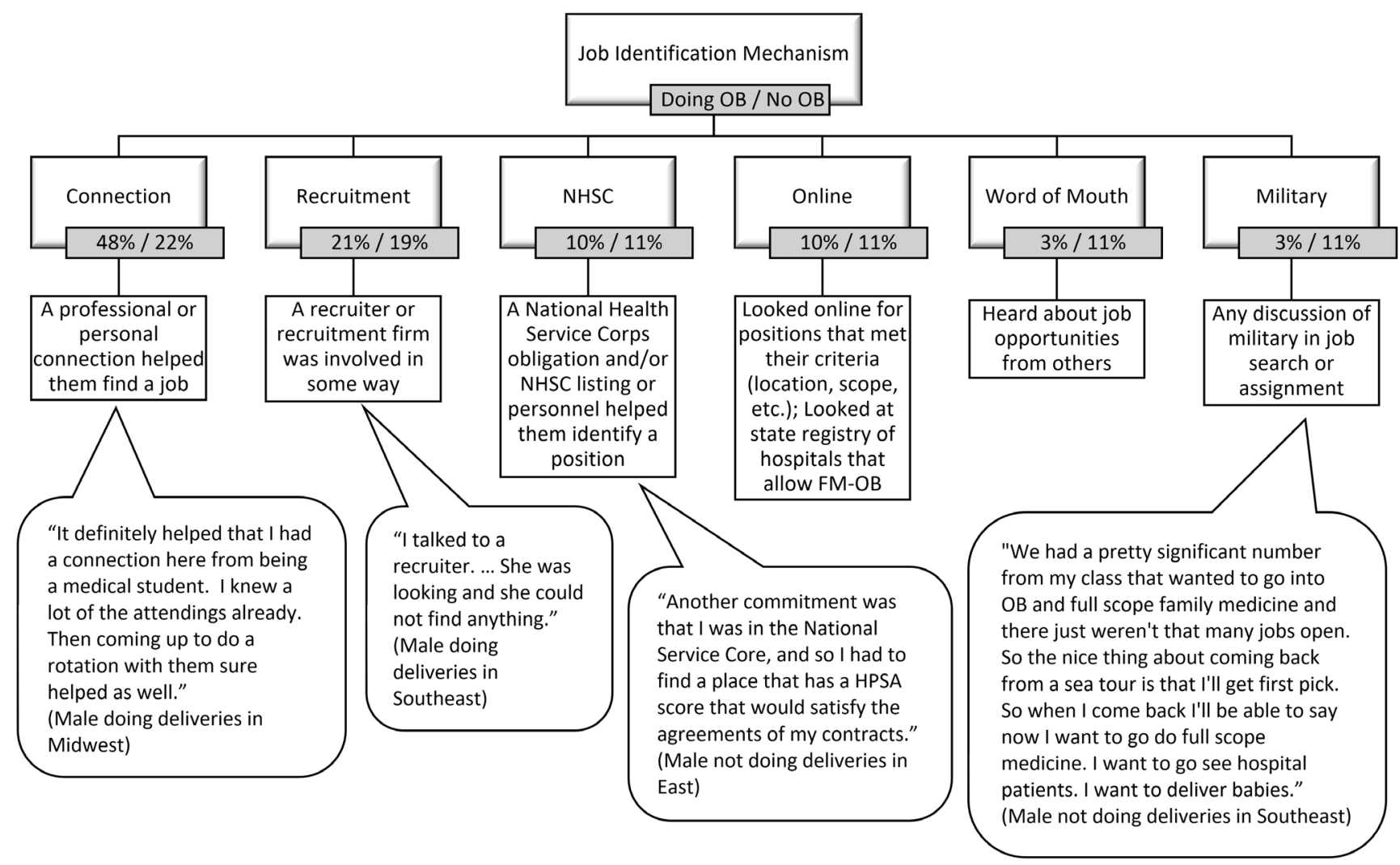

Figure 1 Job identification mechanism: themes and illustrative quotes. OB, obstetrics.

giving up obstetrics while retaining the ability to do other rewarding and related work, such as abortions, women's health, prenatal care or paediatrics. Another group indicated that other competing professional interests drove their decision to take a job without obstetrics. These physicians had done fellowships or had strong residency training in urgent care, sports medicine or emergency medicine and claimed that they could not 'do it all'. Physicians doing obstetrics sometimes discussed professional considerations such as the ability to practice full scope family medicine as a driver in considering a job. Those doing obstetrics were also more likely to discuss being mission focused, to want to work in an academic setting and to seek mentorship in their job.

\section{Role of agency}

A small number of physicians indicated that personal agency played a role in selecting their job. Agency is the capacity as an individual to act independently, to make their own free choices and thus demonstrate individual power. ${ }^{30}$ Agency arose in different ways for those who were doing obstetrics compared with those who were not. Seven family physicians doing obstetrics discussed assertiveness or self-advocacy in asking for obstetrics to be part of their job. Four physicians who were not doing obstetrics indicated that they could have done so, either in their current job or in their current location, but chose not to or chose a job without obstetrics.

\section{Challenges}

Family physicians who were not currently including obstetrics in practice, as well as those who were, discussed the various ways in which it was difficult to identify or obtain a family medicine job with obstetrics (table 3 ). Nine physicians doing obstetrics and eight of those not encountered a lack of availability of jobs with obstetrics in the vicinity of their search. Some were told there were no jobs with obstetrics available, others were actively discouraged by recruiters or employers. Relatedly, physicians described the challenge of needing to overcome the perception or belief that family physicians do not do obstetrics.

Another challenge faced by family physicians wanting to do deliveries in practice included a 'bait-and-switch' offer from an employer that made the physician think that they would be able to do deliveries, but once they were working in the position, they realised that they could not do obstetrics. When newly graduating family physicians took jobs that did not include obstetrics (often taking temporary jobs or doing locums), it became nearly impossible for them to later do obstetrics. Nine of our interviewees not doing obstetrics described a loss of skill or confidence in their ability to do obstetrics as a barrier; two of these described residency programme failure in adequately training or advising.

Almost none of the interviewees identified malpractice as a barrier to doing deliveries. On the contrary, a female physician not doing obstetrics in the West said: 
Table 2 Job decision-making for new family physicians who intend to do obstetrics: themes and illustrative quotes

$\begin{array}{llll}\text { Code } & \text { Code definition } & \text { Illustrative quotes } & \begin{array}{l}\text { Do OB } \\ \text { No OB } \\ n(\%)\end{array}\end{array}$

Theme: personal influences and preferences

Geography/ Constrained by or preference

location

for looking for a job in a here. So it's near grandparents, it's one of the most beautiful small

"[This town is] beautiful. I grew about an hour and a half away from 21 (72) 17 (63)

particular city, region or type of towns in the state). Tons of outdoor activities, rivers, mountains,

geographical area hiking, telemarking, all those things that we loved to do." (Female doing OB in the West)

"I only looked for jobs in Oregon. If it was left to just my career

trajectory, I definitely would have stayed where I trained because

I had built a lot of professional connections there and I knew

that there were a lot of opportunities there for me to practice full

scope." (Female not doing OB in the West)

\begin{tabular}{|c|c|c|c|c|}
\hline Family & $\begin{array}{l}\text { Importance of family (spouse, } \\
\text { parents, etc) in selecting job } \\
\text { and/or location }\end{array}$ & $\begin{array}{l}\text { "...l'm in a two-career household, and both of our careers are } \\
\text { very important to us. Because my spouse had already established } \\
\text { during my residency at one location and that was why I had } \\
\text { come back to [this state] in first place, I knew that I had to stay } \\
\text { somewhat near the [City] Metro area." (Female doing OB in the } \\
\text { Northeast) }\end{array}$ & $12(41)$ & $10(37)$ \\
\hline $\begin{array}{l}\text { Balance/ } \\
\text { lifestyle }\end{array}$ & $\begin{array}{l}\text { Impact of doing OB on } \\
\text { their lifestyle in terms of } \\
\text { family obligations, free time, } \\
\text { convenience or uncertainty }\end{array}$ & $\begin{array}{l}\text { "The expectation was to see like } 40 \text { patients a day on top of like } \\
\text { going in and delivering, and just finding a way to make that work... } \\
\text { didn't sound very realistic to me. I, you know, have a young family. } \\
\text { I need to have like a little bit more predictability as far as my } \\
\text { hours." (Female not doing OB in the West) }\end{array}$ & $3(10)$ & 9 (33) \\
\hline
\end{tabular}

Theme: job characteristics

Practice Attracted by some aspect of

characteristics practice size, composition, structure, etc.

"I took the position I am in now because it's a smaller hospital that $\mathbf{1 3}(\mathbf{3 8}) \quad 0(0)$

is independently owned, so if I have issues I just go talk directly to the CEO instead of 50 other people. And it was a group of family practice physicians, I think there's six or seven of us...that share call and duties, and I run clinical with time to talk to and build collegial type relationships." (Female doing OB in the Midwest)

$\begin{array}{ll}\text { Call/backup } & \text { Call schedule offered by } \\ & \text { job conducive to lifestyle or } \\ & \text { backup available/call schedule } \\ & \text { not ideal or work hour } \\ & \text { expectation too high }\end{array}$

"I also was very interested in joining a place that had OB call pool... If there wasn't an opportunity to be in a pool, I don't know if l'd be doing OB. Because the idea of having my own continuity deliveries and not having kind of that built in time off and kind of that idea of always being on... I really wanted to be in a pool, so basically, I have time when I'm on and I have my time when I'm off.... So that was something that was harder to figure out like kind of get to the phone interview stage with folks and ask that question and really, really wanted that." (Female doing OB in the Northeast)

Payment $\quad$ Financial aspects: job paid

"I feel like it's actually a really big money-maker because I go in for well/job could not pay enough uncomplicated deliveries all the time, like, not of my own people... for work expectations we do all of our own, but obviously, if I go out of town for the weekend, somebody has to cover my OBs. So, I'm covering for people all the time. .... I cover for a lot of people, so sometimes I get huge bonuses I'm not even anticipating. I'm like, why is that? I'm like, "Oh, I did four or five or six extra deliveries." So I think it adds up." (Female doing OB in the West)

\section{Theme: professional considerations and career goals}

$\begin{array}{ll}\text { Good fit } & \text { Found a job that was a 'good } \\ & \text { fit' for them professionally }\end{array}$

"And when I interviewed at $X$ residency program for a faculty position I really liked it and it seemed like it was going to be a good fit for me professionally and personally and then also for my husband's job and our family is all in the [City] area so it was a really good fit." (Female not doing OB in the Midwest)

$\begin{array}{ll}\text { Academic } & \text { Desire for academic position } \\ \text { or one in which they teach }\end{array}$

"The other part that was very attractive to me was because I wanted to be a teacher. I wanted to still teach medical students, I wanted to teach residents just because it was such a meaningful experience for me on the other side. So I also looked at many places where they had teaching openings but ... there were places where you would be on faculty but there is no OB, almost no pediatrics... So that is why this kind of just checked all the boxes for me. (Male doing OB in the Midwest) 
Table 2 Continued

\begin{tabular}{|c|c|c|c|c|}
\hline Code & Code definition & Illustrative quotes & $\begin{array}{l}\text { Do OB } \\
\text { n (\%) }\end{array}$ & $\begin{array}{l}\text { No OB } \\
\text { n (\%) }\end{array}$ \\
\hline Compromise & Job offered something else, & "If this job would have involved delivering babies, it would be & $0(0)$ & $8(30)$ \\
\hline
\end{tabular}
related to OB, like women's perfect. But it didn't. So it was kind of like well you never get health, prenatal care, peds, exactly what you want in a job and I was able to get 9 out of 10. It etc. ended up pretty well. But I hear my residency colleagues talking about delivering babies and I still get some pangs of jealousy that I'm not still doing it." (Female not doing OB in the West)

$\begin{array}{ll}\text { Mission focus } & \text { Importance of working with } \\ \text { underserved populations }\end{array}$

"[My residency] clinic is an FQHC. I fell in love with care for needy communities and my wife is a pharmacist at the hospital as well and she had done some rotations for training with Indian Health Services, so we started our career search in November in our third year and was sort of focusing on Indian health sites...." (Male doing $O B$ in the Southwest)

Other specialty/ Had competing interests interests (sports med, urgent care, ER) and could not 'do it all'; fellowship trained in something other than $\mathrm{OB}$
"During my last year of residency I was looking for a full scope family medicine OB with surgery that was within an hour or so within a large city... During my last year I did a rotation in urgent care, and they were just a good fit. So, where I did rotation, the owner chief medical officer there really liked that I could do all the procedures I could, which is basically like a mini ER. With all the surgical background totally hired me." (Male not doing OB in the West)

Mentorship in job Attracted to job because of mentor in the practice

"Especially out of residency I wanted people I could ask questions to and mentors. There was another reason I didn't like [the idea of] working in that particular practice even though my volume would have been much higher... I just didn't feel comfortable with me being the only person in the practice doing $\mathrm{OB}$ coming right out of residency." (Female doing OB in the West)

Full scope
Importance of the ability to do full scope and/or continuity care
"I think being put in that environment really forces you to stretch your brain and maintain as much the skills that you're trained in as possible. And that was - that was my primary goal after finishing residents choose to come out to a remote location where I would be practicing in a full spectrum capacity, managing OB patients, working in the ER, managing in-patients and really using all of the different assets to the training that we receive." (Male doing OB in the Southeast)

\section{Theme: role of agency}

Selfdetermination

Advocated for themselves to be able to do OB at job
"[Recruiters are] my point of contact when I'm in the job search. So, if you're not determined, and sure [that] this is what you want, and you're not aggressive and assertive in finding the opportunity that will allow you to do what you really enjoy, you may get easily discouraged and stop searching, you know what I mean?" (Female doing $O B$ in the Southeast)

"I was looking for jobs where I could do prenatal care. By the time I started looking for jobs I was pretty sure I didn't want to do deliveries unless my dream job was going to make me do it as a contingency for the job." (Female not doing OB in the Midwest)
It wouldn't be a reason for me to not do it [obstetrics], because if I were to do it, it would be through some larger organization that would take care of the malpractice and liability.

Another female physician doing obstetrics commented: ...they cover all of our malpractice; like all of us who do anything but certainly it includes all of us who do OB. ... the clinic just does that, like it was never an issue, like it was never anything that was even discussed. It was always covered.
While credentialing took some time and effort for most family physicians doing obstetrics, it was generally not discussed as an unreasonable or significant challenge. For example, a physician in the Midwest commented on the privileging process:

It was actually quite extensive, and we had to do 20 observed C-sections before they would give us full privileges. They required an attending during those surgeries. They had to approve our operative logs and submit those from residency and as well as vaginal 
Table 3 Challenges finding family medicine jobs with obstetrics: themes and illustrative quotes

\begin{tabular}{ll}
\hline Theme & Definition \\
\hline Lack of & Lack of availability \\
availability & of FM-OB jobs \\
& overall, in a particular \\
& geographic area
\end{tabular}

Illustrative quotes

"I ended up meeting up with a physician recruiter and told him that I wanted to do family medicine with obstetrics and he told me that I was an odd-duck and that it was going to be hard to find me anything close to where I wanted to be geographically. We did end up finding one place that was about an hour and a half northeast of where I trained that was three other family practice OB physicians in a small rural 24-bed critical access hospital with labor and delivery." (Female doing OB in the Midwest)

"I was surprised when I started looking at how many didn't include OB. So, I had to look specifically for jobs that included OB." (Male doing OB in the West)

"...eventually I ended up moving and I'm practicing rural full spectrum medicine but without $\mathrm{OB}$ in this community also. It's just for me the big barrier is finding a group to practice with and a community that does OB because not every community does OB here." (Male not doing $\mathrm{OB}$ in the Midwest)

"I put out a pretty broad search specifically looking for FM-OB physician in this area and was really surprised to find how little was available in the metro area. It was quite a lot if I wanted to live rurally but I couldn't because of my family situation. I needed to be close to my husband's parent .... really does not have a strong culture of family medicine doctors providing delivery services and that was really surprising to me." (Female not doing OB in the West)

\section{Loss of skill or At the time of} confidence

\section{graduation or after} working in a job that did not include OB, the real or perceived loss of skill made it difficult to obtain a job including $\mathrm{OB}$

\section{Discouragement Discouragement \\ or resistance by employers or recruiters}

\section{Bait and switch Thought could do} OB but after started position, realised could not

$\begin{array}{ll}\text { Perception } & \text { The real or perceived } \\ & \text { perception by } \\ \text { employers, recruiters, } & \text { or consumers that } \\ \text { family physicians do } \\ \text { not do obstetrics }\end{array}$

"For me it was just the situation I found myself in and now(it's)an issue of confidence and credentialing." (Female not doing OB in the West)

"It's just my discomfort with not having enough backup and enough experience and now it's been three years since I've done a delivery. I feel like jumping back in would be pretty tough." (Female not doing OB in the Southeast)

"The thing that is really hurting family medicine docs from doing obstetrics is that if you don't find a job right out of residency, two years goes by, and no one will privilege you anymore. And there's no way for you to like go back, and train to get to the point where you can have obstetric privileges again, or even feel comfortable doing that again." (Female doing $\mathrm{OB}$ in the West)

"I was discouraged when I was speaking to recruiters. ...(They said things like,))'Family docs don't do that anymore. There's too much liability; there's too much risk. No one-it will be hard getting privileges. It would be hard finding a practice that will support you. It will be hard finding an OB group to back you up.' Everything you can find, I was discouraged [by] the recruiters, honestly, because they don't know anything." (Female doing OB in the Southeast)

"When I signed my contract it stated actually that I'm a family physician without OB training who is sort of agreeing to do family medicine healthcare excluding OB care. So I had to talk to them wherever that had a contract to sign for me saying that I was trained with OB. I have OB skills, this is not correct, you have to exclude that, you have to omit it. And then they agreed. So they just said, I'm a family physician trained in the family medicine and I agreed not to do OB, so it didn't say that I was trained...." (Female not doing OB in the Southwest)

"...we started talking to them as a group in residency and, yeah, and so we had kind of talked to them as a group, like, hey this is what we want to do, they had said, yes, you can do that with us. ... So, my first year out of residency, ... we were supposed to start OB at the FQHC clinic. I was with, I mean, it was perfect-my partners and I wanted to do it and then we just-we had buy in with administration but then they really fell through on that and blocked that, in a way." (Male not doing OB in the Midwest)

"Because I don't think that people really understand I'm sufficiently trained, even family medicine can do different kinds of things including delivering babies. A lot of people don't know that, that's kind of an interesting thing too. In old days the family docs did everything and then our older generations, they assume that we do everything. But younger generation they think that we're urgent care people." (Female not doing OB in the Southwest)

OB, obstetrics.

deliveries to be able to get privileges. I also believe that the physician we trained under the most had to write a letter of recommendation as well.... [But] I thought it was reasonable. The last thing that you really want is someone who says they can do something that they can't.

\section{DISCUSSION}

Interviews with early career family physicians who intended to include maternity care in practice demonstrated that they identified and chose jobs after residency in complex and multifactorial ways, with the ability to do obstetrics being one of many factors. Their 
job-seeking behaviours and choices were constrained by both personal factors as well as larger institutional and systems level factors. In terms of finding a job with or without obstetrics after graduation, besides personal considerations like location and family, different themes emerged from physicians currently practising obstetrics versus from physicians not practising obstetrics.

Our interviews confirmed previous research that identified geographical location, personal time and lifestyle as the primary considerations for residency graduates when identifying a job. ${ }^{32}$ However, the nuances of what lifestyle and personal time really mean to physicians and how larger contextual factors like job and practice characteristics play a role in those have not been addressed in the existing literature. Our study showed that geographical location, family or spousal influence and lifestyle considerations were important to most physicians when searching for and accepting a job, but practice characteristics and job structure can mediate these. For example, a job that offers call sharing that reduces scheduling uncertainty can reduce negative impacts on lifestyle and family obligations. For many family physicians, a job structured to support work-life balance is necessary for them to include obstetrics in their practice.

Recruitment of family physicians who do obstetrics was not a common theme among our participants, despite a survey of medical residents that showed they are intensely recruited, with $89 \%$ contacted by recruiters from hospitals, medical groups or recruiting firms at least 10 times during training. ${ }^{32}$ When recruitment was brought up by our interviewees, it was sometimes portrayed as a barrier rather than a facilitator in finding a job that includes obstetrics, indicating that recruiters may not be the best way for family physicians to identify full-scope jobs with obstetrics. It also suggests that employers who choose to use recruiters might better educate the recruiters to fill family medicine-obstetrics positions.

Physicians' freedom to make decisions about what job to take may be constrained by a multitude of job-related issues and professional and personal constraints. Thus, agency and self-efficacy to advocate for desired job scope that includes obstetrics within existing structures is one way family physicians who want to do obstetrics may be able to navigate the system without making professional compromises. Ideally, however, professional and job-related constraints should be minimised so that full-spectrum practice is possible in geographical locations where physicians want and/or need to be given their personal constraints.

This study has several limitations. The sample first self-selected by taking the short survey and further self-selected by agreeing to participate in an interview. It is possible that physicians who did not complete the survey or did not agree to be interviewed had different kinds of experiences than those who made up our interview sample. In addition, because the survey and interview participants were at most 3 years from residency graduation, their experiences only reflect those of early-career physicians, whose careers are not always yet stable. Several interviewees had already changed jobs since graduating.

\section{CONCLUSIONS}

Our findings suggest ways that residency programmes and employers can better support family physicians in maintaining the scope of practice they desire. A recent survey showed that $56 \%$ of residents had not received formal career or business instruction, and another study demonstrated the value of formalised career advising for medical students, which may be extended to residency graduates. ${ }^{32} 33$ Supporting our finding that connections play an important role in identifying desirable jobs, a study on how physicians search for jobs found that $88 \%$ of surveyed physicians rated personal or professional referrals as useful in their search for a job. ${ }^{34}$ Given the challenges of finding jobs that not only include obstetrics but support balance, a more deliberate approach to career advising and a more active role by academic faculty to connect new physicians to jobs with obstetrics may increase the number of family physicians including obstetrics in their practice.

Our data suggest that while employers can alleviate certain challenges faced by family physicians doing obstetrics as cited previously in the literature (by providing malpractice insurance and covering its cost and having a system in place to assist in the privileging process), the physician employment trend may negatively impact physicians looking for jobs that include obstetrics by restricting their ability to do so due to an unfriendly family medicine-obstetrics culture, or if practice characteristics and job structure are not supportive. Employers can further support family physicians who want to include obstetrics by improving call sharing structures and implementing other organisational changes that support work-life balance.

\section{Key points}

\section{Question}

- How do new US family medicine graduates who want to include obstetrics in their scope of practice identify and select jobs?

\section{Finding}

- While newly graduating US family physicians make job decisions based on personal considerations such as geographic preferences, family obligations and lifestyle, their job-seeking and job-taking decisions are constrained by factors beyond their control, such as job structure, employer/practice characteristics and lack of availability of family medicine jobs with obstetrics.

\section{Meaning}

- The shift from physician as practice owner to physician as employee in the USA has implications for job-seeking behaviours of newly graduating medical residents. Because employment influences scope of practice in family medicine, particularly the ability to provide maternity care and deliver babies, it is important to address employer-related barriers.

Acknowledgements The authors would like to thank Lars Peterson for reviewing drafts and providing insightful feedback and Audrey Brock for editing and 
formatting assistance. We greatly appreciate our participants' time and thoughtful responses to our many questions. Aimee Eden had full access to all the data in the study and takes responsibility for the integrity of the data and the accuracy of the data analysis.

Contributors All authors contributed to research design, data collection, data analysis and/or writing the manuscript.

Funding Material support was provided by the American Board of Family Medicine. Competing interests Two authors are or were employed by the ABFM during data collection and analysis: ARE and ERH.

Patient consent for publication Not required.

Ethics approval This study was approved by the American Academy of Family Physicians Institutional Review Board.

Provenance and peer review Not commissioned; externally peer reviewed.

Open access This is an open access article distributed in accordance with the Creative Commons Attribution Non Commercial (CC BY-NC 4.0) license, which permits others to distribute, remix, adapt, build upon this work non-commercially, and license their derivative works on different terms, provided the original work is properly cited, appropriate credit is given, any changes made indicated, and the use is non-commercial. See: http://creativecommons.org/ licenses/by-nc/4.0/.

\section{REFERENCES}

1. Rayburn WF. The obstetrician-gynecologist workforce in the United States. Washington DC: American Congress of Obstetricians and Gynecologists, 2017.

2. ACOG. ACOG Committee opinion no. 586: health disparities in rural women. Obstet Gynecol 2014;123:384-8.

3. Kozhimannil K, Casey M, Hung P, et al. The obstetric care workforce in critical access hospitals (CAHs) and rural Non-CAHs. Minneapolis, MN: University of Minnesota Rural Health Research Center, 2014.

4. Young RA. Maternity care services provided by family physicians in rural hospitals. J Am Board Fam Med 2017;30:71-7.

5. Barreto TW, Eden AR, Petterson S, et al. Intention versus reality: Family medicine residency graduates' intention to practice obstetrics. J Am Board Fam Med 2017;30:405-6.

6. Coutinho AJ, Cochrane A, Stelter K, et al. Comparison of intended scope of practice for family medicine residents with reported scope of practice among practicing family physicians. JAMA 2015;314:2364-72.

7. Tong STC, Makaroff LA, Xierali IM, et al. Proportion of family physicians providing maternity care continues to decline. J Am Board Fam Med 2012;25:270-1.

8. Peterson LE, Fang B, Puffer JC, et al. Wide gap between preparation and scope of practice of early career family physicians. J Am Board Fam Med 2018;31:181-2.

9. Larimore WL, Sapolsky BS. Maternity care in family medicine: economics and malpractice. J Fam Pract 1995;40:153-60.

10. Smits AK, King VJ, Rdesinski RE, et al. Change in Oregon maternity care workforce after malpractice premium subsidy implementation. Health Serv Res 2009;44:1253-70.

11. Fletcher JL, Schwartz MP. Why family practice residents choose not to practice obstetrics. J Med Assoc Ga 1989;78:559-61.

12. Koppula S, Brown JB, Jordan JM. Experiences of family medicine residents in primary care obstetrics training. Fam Med 2012;44:178-82.

13. Chen FM, Huntington J, Kim S, et al. Prepared but not practicing: declining pregnancy care among recent family medicine residency graduates. Family Medicine-kansas City 2006;38.
14. Tucker W, Diaz V, Carek PJ, et al. Influence of residency training on procedures performed by South Carolina family medicine graduates. Fam Med 2007;39.

15. Eden AR, Peterson LE. Challenges faced by family physicians providing advanced maternity care. Matern Child Health $J$ 2018;22:932-40.

16. Barreto TW, Eden AR, Hansen ER, et al. Barriers faced by family medicine graduates interested in performing obstetric deliveries. $J$ Am Board Fam Med 2018;31:332-3.

17. The Physicians Foundation. 2016 survey of American's physicians, 2016. Available: https://physiciansfoundation.org/wp-content/ uploads/2018/01/Biennial_Physician_Survey_2016.pdf

18. Kane C. Updated data on physician practice arrangements: physician ownership drops below 50 percent, 2017. Available: https://www.ama-assn.org/sites/default/files/media-browser/public/ health-policy/PRP-2016-physician-benchmark-survey.pdf

19. Hancock C, Steinbach A, Nesbitt TS, et al. Why doctors choose small towns: a developmental model of rural physician recruitment and retention. Soc Sci Med 2009;69:1368-76.

20. Parlier AB, Galvin SL, Thach $S$, et al. The road to rural primary care: a narrative review of factors that help develop, recruit, and retain rural primary care physicians. Acad Med 2018;93:130-40.

21. Tong ST, Hochheimer CJ, Barr WB, et al. Characteristics of graduating family medicine residents who Intend to practice maternity care. Fam Med 2018;50:345-52.

22. Bennett KL, Phillips JP, Finding PJP. Finding, recruiting, and sustaining the future primary care physician workforce: a new theoretical model of specialty choice process. Acad Med 2010;85:S81-S88.

23. Reed VA, Jernstedt GC, Reber ES. Understanding and improving medical student specialty choice: a synthesis of the literature using decision theory as a referent. Teach Learn Med 2001;13:117-29.

24. Creed PA, Searle J, Rogers ME. Medical specialty prestige and lifestyle preferences for medical students. Soc Sci Med 2010;71:1084-8.

25. Rogers ME, Creed PA, Searle J. The development and initial validation of social cognitive career theory instruments to measure choice of Medical specialty and practice location. J Career Assess 2009;17:324-37.

26. Senf JH, Campos-Outcalt D, Kutob R. Factors related to the choice of family medicine: a reassessment and literature review. J Am Board Fam Pract 2003;16:502-12.

27. Barreto TW, Eden A, Hansen ER, et al. Opportunities and barriers for family physician contribution to the maternity care workforce. Fam Med 2019;51:383-8.

28. United States Department of Agriculture. Rural-urban commuting area codes 2010. Available: https://www.ers.usda.gov/dataproducts/rural-urban-commuting-area-codes.aspx

29. Borkan J, Crabtree B, Miller W. Immersion/crystallization. Doing qualitative research. 2nd ed. Thousand Oaks, CA: Sage Publications, 1999: 179-94.

30. Ahearn LM. Language and agency. Annu Rev Anthropol 2001;30:109-37.

31. Solberg VS, Good GE, Fischer AR, et al. Career decision-making and career search activities: relative effects of career search self-efficacy and human agency. J Couns Psychol 1995;42:448-55.

32. NEJM Career Center. Recruiting physicians today. NEJM Career Centerorg, 2015: 23.

33. Sastre EA, Burke EE, Silverstein E, et al. Improvements in medical school wellness and career counseling: a comparison of oneon-one advising to an Advisory College program. Med Teach 2010;32:e429-35.

34. NEJM Career Center/ Zeldis Research Associates. How physicians search for jobs 2010. Available: http://employer.nejmcareercenter. org/rpt/jobstudy10.pdf 